\title{
A Rare Non-motor Symptom of Parkinson's Disease: Severe Pain Mimicking Pain of Radicular Origin
}

\author{
Parkinson Hastalığı'nın Nadir Bir Motor Dışı Belirtisi: Radiküler

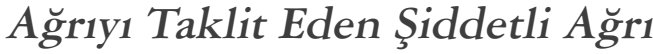

\author{
(1) Halil Önder ${ }^{1}$, (1) Umut D. Aktürk² \\ ${ }^{1}$ Yozgat City Hospital, Clinic of Neurology, Yozgat, Turkey \\ ${ }^{2}$ Yozgat City Hospital, Clinic of Neurosurgery, Yozgat, Turkey
}

Keywords: Non-motor symptom, radicular pain, Parkinson's disease, pathophysiology

Anahtar Kelimeler: Motor dışı belirti, radiküler ağrı, Parkinson hastalığı, patofizyoloji

\section{Dear Editor,}

Herein, a 51-year-old male patient is described who attended to our neurosurgery outpatient unit with symptoms of severe, penetrating pain starting from the left shoulder and extending to the forearm. He had a past history of Parkinson's disease (PD) for the last three years, which had started with left-sided slowness and gait disturbance. There was distant consanguinity between his parents. Initially, treatment with rasagiline and ropinirole (titrated up to $24 \mathrm{mg}$ per day) was started. However, due to impulsive and compulsive behaviors (including hypersexuality and compulsive shopping) that occurred under ropinirole therapy, the dose was lowered to $8 \mathrm{mg} /$ day and levodopa/carbidopa/entacapone $3 \times 75 / 18.75 / 200 \mathrm{mg}$ was added to the therapy for severe leftsided bradykinesia and gait difficulty. Besides the patient reported that he had been experiencing severe, shoulder-forearm pain accompanied by tingling reminiscent of radicular pain for the past six months, in addition to neck pain. At that time, cervical magnetic resonance imaging was performed, which showed central disc protrusion at C6-7, suggesting that radiculopathy could be the cause of the new-onset shoulder pain (Figure 1). Nonsteroidal anti-inflammatory drugs (NSAIDs) provided a partial relief in his symptoms. Subsequently, the patient was referred to the neurology unit for neurologic and electrophysiologic investigations. The neurologic examination including sensorial and motor assessments was unremarkable and deep tendon reflexes were bilaterally normoactive. The pain area roughly corresponded to C5-7 dermatome, and the left-sided bradykinesia and rigidity were prominent during the "off-period", but dystonic posture or dyskinesia were not observed. Detailed needle electromyography investigation including left C5-8-T1 myotomes (deltoid, biceps brachii, triceps, $1^{\text {st }}$ dorsal interosseous) were normal, which warranted a re-assessment of the diagnosis. Detailed re-evaluation of the medical history revealed episodes of transient, partial recovery from pain, which were described as occurring soon after levodopa/ carbidopa/entacapone dose by the patient (he elaborated upon this when the symptom was specifically questioned). Taken together, pain was rather considered as a non-motor symptom (NMS) of $\mathrm{PD}$, and the levodopa/carbidopa/entacapone dose was increased

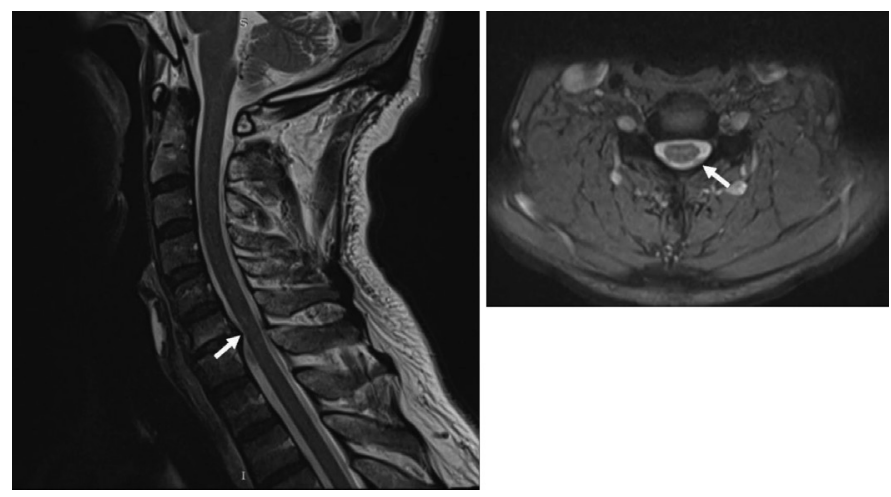

Figure 1. Cervical magnetic resonance imaging showing central disc protrusion at C6-7 level

Address for Correspondence/Yazışma Adresi: Halil Önder MD, Yozgat City Hospital, Clinic of Neurology, Yozgat, Turkey

Phone: +90 5376836864 E-mail: halilnder@yahoo.com ORCID ID: orcid.org/0000-0002-1823-2278

Received/Geliş Tarihi: 11.03.2018 Accepted/Kabul Tarihi: 02.09.2018

${ }^{\oplus}$ Copyright 2018 by Turkish Neurological Society

Turkish Journal of Neurology published by Galenos Publishing House. 
up to $3 \times 100 / 25 / 200 \mathrm{mg}$, resulting in a significant improvement of symptoms. However, following the dose increment, levodopainduced upper extremity dyskinesia rapidly developed during the "on-time", requiring the addition of low dose amantadine $(2 \times 50$ $\mathrm{mg}$ ) to the treatment for control of dyskinesia at subsequent follow-up visits.

NMSs have gained recent attention for their impact on quality of life in PD patients, as well as for their prognostic relevance $(1,2)$. NMSs are known to occur in more than $90 \%$ of patients with PD (1). Although the underlying pathophysiology is still poorly understood, dysfunction of both dopaminergic and nondopaminergic systems has been accused (1). The most commonly reported NMSs include fatigue, anxiety, insomnia, pain, and urgency (1). Among these symptoms, the clinical relevance of pain as an NMS of PD and underlying mechanisms have particularly constituted interesting subjetcs for further investigations (1,2,3). Approximately 40-61\% of patients with PD have been reported to experience pain or unpleasant sensations (1). However, a wide range of pain types has been described in patients with PD (other than NMSs, such as musculoskeletal, dystonic or radicular pain) $(3,4)$; a pathophysiologic distinction among these pain types is very challenging. On the other hand, radicular pain is a frequent type of pain in patients with $\mathrm{PD}$, reported in about $14-27 \%$ of cases $(4,5)$.

To the best of our knowledge, a detailed description of a patient with NMS mimicking radicular pain has not been reported previously. Therefore, we believe that the patient described herein may represent an interesting case illustration. Also, we wish to emphasize that pain may manifest in distinct scenarios suggesting a variety of different diagnoses in patients with PD as in our case, and we consider pain as a crucial NMS in PD, which should be kept in mind by physicians. The clinical response to levodopa may give some insights regarding the pathophysiology of pain as an NMS, supporting the dopaminergic hypothesis. However, the initial partial response to NSAIDs led us consider more complex underlying mechanisms. Additionally, on-time dyskinesia developed soon after the increment of levodopa dose, whereas a significant concurrent amelioration of ipsilateral pain was achieved, supporting the association between NMS and motor complications as previously mentioned by Tinazzi et al. (3).

A major limitation in this case is the possible contribution of an underlying actual radicular pain which cannot be fully ruled out as electrophysiologic investigations fail to provide high sensitivity and specificity required for confirming a root injury (6). Of note, dopaminergic treatment may also relieve other types of musculoskeletal pain or radicular pain, via an indirect mechanism that involves the amelioration of parkinsonian motor symptoms (7). However, diurnal fluctuation of the pain and significant response to levodopa were rather supportive of an underlying NMS in our patient. Future reports of larger case series including followup data and response to medication in these patients are surely warranted to clarify these discussions.

\section{Ethics}

Informed Consent: Consent form was filled out by all participants.

Peer-review: Internally peer-reviewed.

\section{Authorship Contributions}

Surgical and Medical Practices: H.Ö., U.D.A., Concept: H.Ö., Design: H.Ö., Data Collection or Processing: H.Ö., U.D.A., Analysis or Interpretation: H.Ö., Literature Search: H.Ö., U.D.A., Writing: H.Ö.

Conflict of Interest: No conflict of interest was declared by the authors.

Financial Disclosure: The authors declared that this study received no financial support.

\section{References}

1. Barone P, Antonini A, Colosimo C, et al. The PRIAMO study: A multicenter assessment of nonmotor symptoms and their impact on quality of life in Parkinson's disease. Mov Disord 2009;24:1641-1649.

2. Findley L, Aujla M, Bain PG, et al. Direct economic impact of Parkinson's disease: a research survey in the United Kingdom. Mov Disord 2003;18:11391145 .

3. Tinazzi M, Del Vesco C, Fincati E, et al. Pain and motor complications in Parkinson's disease. J Neurol Neurosurg Psychiatry 2006;77:822-825.

4. Goetz CG, Tanner CM, Levy M, Wilson RS, Garron DC. Pain in Parkinson's disease. Mov Disord 1986;1:45-49.

5. Valkovic P, Minar M, Singliarova H, et al. Pain in Parkinson's Disease: A Cross-Sectional Study of Its Prevalence, Types, and Relationship to Depression and Quality of Life. PLoS One 2015;10:e0136541.

6. Charles JA, Souayah N. EMG/NCS in the evaluation of spine trauma with radicular symptoms. Neurol Clin Pract 2013;3:8-14.

7. Ozturk EA, Gundogdu I, Kocer B, Comoglu S, Cakci A. Chronic pain in Parkinson's disease: Frequency, characteristics, independent factors, and relationship with health-related quality of life. J Back Musculoskelet Rehabil 2016. [Epub ahead of print] 